\title{
NEW CONSUMERS OF THE DIGITAL AGE: GAME PLAYERS
}

\author{
Asst. Prof. Erkan BíL (iD) 1
}

\section{Asst. Prof. Hande KANDUR (iD ${ }^{2}$}

\section{Asst. Prof. Senem ERGAN ${ }^{3 *}{ }^{3 *}$}

\author{
1 Çanakkale Onsekiz Mart University, Faculty of Political Sciences, erkanbil@comu.edu.tr \\ 2 Çanakkale Onsekiz Mart University, Gökçeada School of Applied Sciences, handekandur@comu.edu.tr \\ 3 Çanakkale Onsekiz Mart University, Gökçeada School of Applied Sciences, senemergan@comu.edu.tr *Correspondent Author
}

\section{Article history:}

Submission 05 August 2021

Revision 19 October 2020

Accepted 01 December 2021

Available online 31 December 2021

\author{
Keywords: \\ Game, \\ Game Player Behavior, \\ Characteristics of Game Players, \\ Time Spent Playing, \\ Gamescom.
}

DOI:

https://doi.org/10.32936/pssj.v5i3.272

\begin{abstract}
A b s t r a c t
The game market has become one of the fastest growing industries of the digital age. The availability of internet access from anywhere, the diversification of game platforms, the increase in game options and the increase in application stores especially for mobile devices have accelerated this growth in the sector. The purpose of this study was to determine who the new consumers in the developing game industry are, their various demographics, characteristics and purchasing behaviors. Data which were collected by the survey method from 490 game players who participated in Gamescom, the world's largest game fair held in Cologne, Germany between 20-24 August 2019, were analyzed by descriptive statistics, t-test and one-way anova. As a result of the findings, it has been determined that majority of the participants were female, young adults and students. Almost half of the participants have more than 12 years of gaming experience, play games for an average of 3.76 hours a day and an average of 5.16 days per week, prefer to play at home and on their personal computers the most, majority were core gamers, and the favorite game category was action.
\end{abstract}

\section{Introduction}

Gamescom is the world's largest interactive trade fair, founded in 2009. Investors, game developers, distributors and game lovers show great interest in the fair held in Cologne, Germany every year (Electronic Arts, 2020). 373,000 people from more than 100 countries visited Gamescom 2019. In addition, 31.300 trade visitors and 1.153 companies participated in the fair (PC Games Insider, 2019)

When examined on a global basis, the video game market has an important business volume. Today, the value of the global game market has reached 231.6 billion dollars. One of the most important reasons for this result can be shown as the rapid digitalization of the video game industry. It is known that today there are more than 2.4 billion players worldwide, in addition to this, the mobile game market accounts for $47 \%$ of the total sales of the game industry. Looking at the game preferences, it is seen that mobile games outperform the console (28\%) and the computer (25\%). Today, 2.87 billion people using smartphones worldwide (Statista, 2020a). The fact that the distribution speed and volume of online mobile games are higher than offline games causes players to prefer online games more and abandon game consoles and turn to smart phones (San-Martin et al., 2020). Thanks to the application stores developed for mobile devices, an improved channel was provided for game development companies to easily distribute their games, and as a result, the time to market the games was greatly reduced (Lee et al., 2020).

According to a study, the time spent by mobile phone users on their phones on a daily basis increased from 152 minutes in 2014 to 215 minutes in 2018. Half of the time internet users spent online in 2019 was on mobile devices. However, this period was $27 \%$ in 2013. It is known that the largest mobile game region worldwide is the Asian continent. Revenues from the mobile gaming market in the Asian continent in 2018 exceeded US \$ 41.5 billion. In 2018, it generated revenue of US \$ 33.2 billion and US \$ 30.1 billion, respectively, from both Apple and Google mobile game app stores. Candy Crush Saga, a sugar-based strategy game that first started to be played on mobile phones as a mobile application in 2012, has shown that it is one of the most successful 
mobile games of all time, with over one billion US dollars' player spending worldwide in 2018 (Statista, 2020c). According to another study, global mobile gaming revenue is expected to grow from US \$ 77.2 billion in 2020 to US \$ 102.8 billion in 2023 (Statista, 2020a). As can be seen, over the years, changes have been observed in the tools and habits that online users use to access the Internet. This situation has also affected the gaming industry and online games have now become available to consumers as mobile games.

The development of the gaming industry has created an intriguing field of research, especially for marketing academics and professionals looking for new promotional channels. Answers to questions such as who are the new consumers created by the developing game industry, their purchasing behavior, and their purchase frequency have started to be sought. This study, based on these questions, aims to examine the demographic features and purchasing profiles of game players. For this purpose, the concept of game was mentioned first, and then information about the data collected within the scope of the research was given, methods and analyses were explained. In the last section, the results obtained were shared, discussed, and suggestions for future research were given.

\section{Game}

The game industry is a sector that is developing day by day. Today, game platforms are diversifying depending on the development of technology. Thanks to platforms such as consoles, computers, mobile phones, tablets, players can play games online and offline (Scharkow et al., 2015).

The first examples of computer games are Tennis for Two, developed in 1958, and Spacewar, developed in 1962, which created both commercial and social impact. The first game console, Brown Box, was released in 1968. Pac-Man, released by Namco in 1980, is the first major game about friendship and humor. It also attracted the attention of girls and young women, creating a growth in the game market. Nintendo released the handheld game console Gameboy in 1989. In 1994, Sony put on sale the game console called Playstation. The foundation of mobile games was laid with the Snake game that is included in Nokia mobile phones. The popularity of social networks has created a new market for daily games (Karahisar, 2013).

Game consoles are needed to play video games. Game consoles are computer-based devices that allow games to be played directly by connecting to the TV. The best known are PlayStation (Sony), XBOX (Microsoft) or Nintendo (Microsoft) (Ankara Development Agency, 2015).

Table 1. Worldwide Sales of Video Game Consoles (2020)

\begin{tabular}{ll}
\hline Video Game Console & Number of Sales (Million) \\
\hline PlayStation 2 (PS2) & 157.68 \\
Nintendo DS (DS) & 154.90 \\
Game Boy (GB) & 118.69 \\
PlayStation 4 (PS4) & 112.96 \\
PlayStation (PS) & 102.50 \\
Nintendo Wii (Wii) & 101.64 \\
PlayStation 3 (PS3) & 87.41 \\
Xbox 360 (X360) & 85.80 \\
Game Boy Advance (GBA) & 81.51 \\
PlayStation Portable (PSP) & 81.09 \\
\hline
\end{tabular}

Source: Statista (2020b); VGChartz (2020).

As seen in Table 1, the most popular video game consoles in the world are listed as PlayStation 2, Nintendo DS and Game Boy. With the digitalization of the society, digital games are becoming widespread and this proliferation continues to increase. Digital games have turned into a mass media that reaches millions of people. Although the games are generally aimed at young players, they attract players of all ages (Terlutter \& Capella, 2013).
Digital games are in high demand, and many gamers have turned them into leisure pursuits. Mobile devices and social media platforms have become vital platforms for playing popular games in recent years. Digital games are multiplayer games that allow users to dream and have fun, despite the fact that they are entertainment-oriented and internet-based information technology. Playing digital games in the mobile environment has become more popular, especially with the evolution of smartphones, since it expands the amount of space and time 
available time for users to play games (Rafdinal \& Qisthi, 2020). Digital games are interactive electronic games with a user interface. It can be played in a variety of ways, whether online or offline, single player versus artificial intelligence, or multiplayer versus each other or versus artificial intelligence. There are game types such as network, sports, action, racing, puzzle, role-playing games, simulation, adventure and strategy according to the preferences of the players (Güvenli Web, 2017).

Table 2. Digital Game Types and Examples

\begin{tabular}{ll}
\hline Game type & For example \\
\hline Tactics & Chess, Dune 2, Tycoon Series, Warcraft, Starcraft, Age of Empires \\
Jigsaw & Angry Birds, Diamond Crush, Tetris, Frozen Bubble, Luxor, Sudoku Gridmaster \\
Adventure & The Longest Journey, Indiana Jones, Myst and Riven \\
Action & Pac-Man, Call of Duty: Advanced Warfare, Grand Theft Auto, Far Cry, Dragon Age: Inquisition, Assassin's Creed \\
& \\
Sport & FIFA, NBA, Skating, Tennis, Championship Manager \\
Role play & Dungeons \& Dragons, Ever-Quest, Diablo, World of Warcraft \\
Simulation & Sim City, The Sims, Airplane Simulators, Trauma Center \\
\hline Source: Yalçn Irmak \& Erdoğan (2016).
\end{tabular}

Source: Yalçın Irmak \& Erdoğan (2016).

With the development of technology, there has been a change in games and mobile games have entered the gaming industry. Mobile games are video games played on a mobile device such as a smartphone or tablet. The development of smart phones and the existence of mobile internet are changing the conditions of mobile games. Touch screens, higher quality graphics resolution, and access to networks everywhere provide users with a better gaming experience. Players who play mobile games can download various games from online application stores and access them more easily than games on other platforms. Mobile games are also played through social networks. Such mobile games are called mobile social games. Thanks to mobile social games, a player can meet and socialize with other players (Hsiao \& Chen, 2016:19). According to Deloitte's research, most play mobile games countries in the world are Turkey (55\%), South Korea (53\%), India $(53 \%)$ and China $(51 \%)$. In the research, it ranks first with single-player games (78\%) (Deloitte, 2019).

Game playing time determines the level of habit that game players develop about a game. Studies show that habit has a significant effect on loyalty and continuity of usage (Lin \& Wang 2006; Venkatesh et al., 2012). Therefore, playing time of game players are important issues for game developers. When the academic studies about the game are examined, it is seen that the playing time is added to the research model in many of them. In the study conducted by Hsiao \& Chen (2016) with 3309 game players, $44.86 \%$ of the participants stated that they played games for 1-3 hours a day. They have found that habit and platform affect in-app purchase intention, whereas the influences of the other demographics (age, gender, income) are not significant. Griffiths et al. (2004b) and Herodotou et al. (2015) have found that game playing time is inversely proportional to age. In another study, Cole \& Griffiths (2007) have found that game players who play online games waste much more time than the game players who play offline. As a result, they have found that there is a positive relationship between the game playing time and the number of friends in the game. Winn \& Heeter (2009) asked the participants "when was the last time you played a digital game". The answers indicate that male participants play games more frequently than female participants (for example, the ones who answered as today; female $7.4 \%$ - male $41.2 \%$, the ones who answered as longer than 6 months; female $32.6 \%$ - male $3.5 \%$ ). However, Williams et al. (2008) have found that older game players and female game players play more in their research. As it can be seen, game playing time is affected by variables such as gender, age, and style of playing (online-offline).

Player types have also been classified in different ways over time. One of the first classifications for computer games was made by Bartle (1996). Bartle (1996) classified the players according to their approach to playing the MUD game; achievers, explorers, socializers or killers. Achievers aim to follow the rules and reach or win goals. The successful ones like to level up or accumulate points. Explorers enjoy interacting with the game's world. They like learning about the game's world and discovering new areas. They are extremely inquisitive and like taking on new challenges. Socializers usually look for a social environment where they may meet new people and so they can connect with other players. They have proclivities to be in communication. Killers are socially motivated individuals who like dominating and defeating their opponents. They are competitive and also they are eager to seek and learn new ideas and strategies to be successful (Lipinski et al., 2017). Later, Schuurman et al. (2008) made a classification based on players' motivations; the overall convinced gamer or fan 
boy, the convinced competitive gamer or competitor, the escapist gamer and the pass-time gamer or time killer. In the next classification, the players are classified as casual gamer and hardcore gamer by looking at various parameters such as average playing time, average game session duration, time spent by the players during the game and their attitudes. Hardcore gamers, on average, play more than an hour a day, buying their own games. They persistently resist playing the same game with a much higher interest than average. They are active in the gaming communities and the forums they are members of. Casual gamers, on the other hand, spend less time playing games and display an ordinary attitude towards the game (Poels et al., 2012). Core gamers are between casual gamers and hardcore gamers. They are more selective in games than casual gamers. Newbie gamers do not know much about the game and they are inexperienced. They consult their environment (family, friends, etc.) when starting a new game or researching a new game. They often play games to relieve their boredom (Rogers, 2012). There are many studies on "game" in the literature. While some of these studies are aimed at determining the profile of game players, some of them examine game players from a behavioral perspective. In almost all of these studies, the number of "male game players" is higher than "female game players". Table 3 shows results in the gender of game players belonging to previous studies.

Table 3. Gender Findings of Game Players in Previous Studies

\begin{tabular}{ll}
\hline Source & Result \\
\hline Griffiths et al. (2003) & $\begin{array}{l}\text { Males play online games more than females (84\% of participants are male for Everlore fan site, } 86 \% \text { of } \\
\text { participants are male for Allakhazam fan site) }\end{array}$ \\
Griffiths et al. (2004a) & $\begin{array}{l}\text { Males play online games more than females (81\% of participants are male players) } \\
\text { Males play massively multiplayer online games more than females (80.80\% of participants are male } \\
\text { Williams et al. (2008) }\end{array}$ \\
players) \\
Hainey et al. (2011)
\end{tabular}

As can be seen, male game players are more than female game players. The studies are mostly based on online games. For example, Grififths et al. (2003) worked on fan sites of two famous online games (Everlore \& Allakhazam). Williams et al. (2008) studied with players who played EverQuest 2. Previous studies show that men are more active in the game industry. But, genderbased habits are not at the forefront for the "Generation Z", the new generation of consumers. For example, according to the study of Pew Research Center, Generation Z does not see the "gender" factor as important (Pew Research Center, 2018). One of the aims of this study is to find a different result than previous gender-based studies. Besides, there is no study in a game fair in the game literature. In this sense, this study is also a first with regards to the research environment. While determining the study questions, the missing details in the literature were determined and the main lines of the study were formed according to these missing details. It is seen that previous studies are generally about game players who play a specific game or only play online or offline games. However, this study does not focus on a specific game and includes game players who play online and offline games. In addition to these, there are deficiencies regarding playing place and game platforms in the literature.

Despite all these developments mentioned in the game market, academic research's in this area is relatively scarce. However, most of the research is built on a certain constraint such as video games, console games, mobile games, online games etc. This study is carried out to determine the general characteristics of game players attending the Gamescom Fair without any restrictions mentioned above. Specifically, this paper aims (1) to explore the demographics of game players and (2) to determine the characteristics of game players and (3) to specify whether the amount of time spent playing games differ in terms of various demographics and characteristics of the game players. So, the following research questions and hypotheses are proposed:

RQ1: What are the demographics of game players?

RQ2: What are the characteristics of game players such as playing history, playing habits and purchase behavior?

RQ3: What are the characteristics of game players in terms of gender, age and education?

H1: The amount of time spent playing games per day differs depending on gender of the players.

H2: The amount of time spent playing games per day differs depending on age of the players.

H3: The amount of time spent playing games per day differs depending on education level of the players.

H4: The amount of time spent playing games per day differs depending on occupation of the players.

H5: The amount of time spent playing games per day differs depending on gamer type of the players. 
H6: The amount of time spent playing games per day differs depending on game experience of the players.

\section{Methodology}

\subsection{Participants}

The sample of the research consists of 490 game players who participated Gamescom fair in Cologne, Germany in 2019. The convenience sampling method, one of the non-probability sampling methods, was followed in the study and face-to-face survey technique was used as a data collection tool (Etikan et al., 2016).

\subsection{Measures}

Basic demographic measures used in the first part of the survey instrument. Game players were asked for their gender, age, education, occupation and monthly income. In the second part of the survey data collected relating to characteristics of game players. Participants were asked for their playing history (e.g. how many years they had been playing games) and playing frequency (i.e. how many hours they play games in a day, how many days they play games in a week). Also data collected relating to playing habits of game players. For this purpose, the questions were asked relating to playing place (e.g. home, cafe, workplace, gaming platform (i.e. Xbox, PlayStation, PC) and lastly participants were asked whether they play online or offline games. Participants were also asked for gamer type (e.g. hardcore, core, casual, newbie), favorite game category (e.g. action, adventure, card) and favorite game (open-ended). In the last part of the survey instrument players asked for their purchasing behavior, including purchasing costs of items per a month, purchase items (e.g. currencies, level up items, weaponry) and whether they update their PC, console or tablet (e.g buy a new one) to be able to play new games or the latest version of a game. While creating the survey instrument which consists of 17 questions in total, literature review and expert opinions were used.

\subsection{Statistical Analysis}

The analysis of data consisted of two stages. First, demographics and characteristics of the game players had been put forward through frequency analyses, graphics and contingency tables to answer the research questions. Second, in order to test the hypotheses t-test and ANOVA were used to determine whether the time spent playing games differs according to demographic (age, gender, education, profession) and characteristic (game type, game experience) variables of the game players. For this purpose, $t$-test and ANOVA were used to determine if significant difference exist among different groups of game players with the use of an appropriate post-hoc test. All analyses were conducted using SPSS 20

\subsection{Findings}

In order to determine the demographic measures of game players, their gender, age, educational status, occupation, income status was asked. The detailed demographic measures of 490 game players are presented in Table 4.

Table 4. Demographics of Game Players

\begin{tabular}{llcc}
\hline Characteristics & & Frequency & $\%$ \\
\hline Gender & Male & 117 & 23.9 \\
Age & Female & 373 & 76.1 \\
& $10-15$ & 43 & 8.8 \\
& $16-20$ & 126 & 25.7 \\
& $21-25$ & 166 & 33.9 \\
Education & $26-30$ & 81 & 16.5 \\
& $>30$ & 74 & 15.1 \\
& High school and under & 328 & 66.9 \\
Occupation & Bachelor & 114 & 23.3 \\
& Master and above & 48 & 9.8 \\
& Student & 209 & 42.7 \\
& Office worker & 115 & 23.5 \\
& Self-employed & 35 & 7.1 \\
& Other & 131 & 26.7 \\
& Less than min. wage in my country & 55 & 11.2 \\
& Min. wage in my country & 111 & 22.7
\end{tabular}


Between 6 and 10 times of min. in my country wage $\quad 30 \quad 6.1$

Over 10 times of min.wage $\quad 20$

No monthly income

Table 4 contains information on the demographic measures of the game players who participated in the survey. $76.1 \%$ of the game players were female and $23.9 \%$ were male. $33.9 \%$ of the participants were in the 21-25 age range, the education level of
$66.9 \%$ is "high school and under" and $42.7 \%$ was student. $29.8 \%$ of the participants stated that their monthly income was between 2 and 5 times of min. wage in their country.

Table 5. Playing History and Frequency of Game Players

\begin{tabular}{llll}
\hline Playing History & & Frequency & $\%$ \\
\hline Game experience & $<1$ year & 8 & 1.6 \\
& $1-3$ years & 45 & 9.2 \\
& $4-6$ years & 65 & 13.3 \\
7-9 years & 54 & 11.0 \\
$10-12$ years & 71 & 14.5 \\
Game playtime per day & $>12$ years & 247 & 50.4 \\
& $1-3$ hours & 276 & 56.3 \\
Playing days per week & $4-6$ hours & 155 & 31.6 \\
& $7-9$ hours & 39 & 8.0 \\
& More than 10 hours & 20 & 4.1 \\
& One day & 16 & 3.3 \\
& Two days & 45 & 9.2 \\
& Three days & 52 & 10.6 \\
& Four days & 59 & 12.0 \\
& Five days & 79 & 16.1 \\
& Six days & 40 & 8.2 \\
Everyday & 199 & 40.6 \\
\hline
\end{tabular}

According to Table 5, it is seen that almost half of the participants $(50.4 \%)$ have more than 12 years of gaming experience. While
$56.3 \%$ stated that they play $1-3$ hours per day, $40.6 \%$ stated that they play games every day.

Table 6. Playing Habits of Game Players

\begin{tabular}{llll}
\hline Playing Habits & & Frequency & $\%$ \\
\hline Playing place & House & 481 & 73.3 \\
& Cafe & 114 & 17.4 \\
& Workplace & 26 & 4.0 \\
Game platform & Other & 35 & 5.3 \\
& Xbox & 5.9 & 23.2 \\
& PlayStation & 68 & 16.5 \\
& Nintendo & 268 & 33.6 \\
Playing offline/online & PC & 190 & 15.4 \\
& Mobile & 387 & 4.2 \\
& Tablet & 177 & 1.3 \\
& Other & 48 & 69.8 \\
\hline
\end{tabular}




\begin{tabular}{lll}
\hline Total & 490 & 100.0 \\
\hline
\end{tabular}

The majority of game players preferred to play game in their houses $(73.3 \%)$. Game players who participated in the research stated that they mostly prefer PC (33.6\%) as a game platform and $69.8 \%$ of the game players stated that they play online games.

Table 7. Types, Favorite Game Category's' and Favorite Games' of Players

\begin{tabular}{|c|c|c|c|}
\hline \multicolumn{2}{|c|}{ Types, Favorite Game Category's' and Favorite Games' of Players } & \multirow{2}{*}{$\begin{array}{l}\text { Frequency } \\
26\end{array}$} & \multirow{2}{*}{$\begin{array}{l}\% \\
5.3\end{array}$} \\
\hline Gamer type & Newbie & & \\
\hline & Casual gamer & 163 & 33.3 \\
\hline & Core gamer & 213 & 43.5 \\
\hline & Hardcore gamer & 88 & 18.0 \\
\hline \multirow[t]{10}{*}{ Favorite game category } & Action & 317 & 20.4 \\
\hline & Adventure & 268 & 17.2 \\
\hline & Card & 55 & 3.5 \\
\hline & Puzzle & 46 & 3.0 \\
\hline & Racing & 85 & 5.5 \\
\hline & Roleplaying & 260 & 16.7 \\
\hline & Sports & 79 & 5.1 \\
\hline & Strategy & 224 & 14.4 \\
\hline & Simulation & 126 & 8.1 \\
\hline & Other & 97 & 6.2 \\
\hline \multirow[t]{11}{*}{ Favorite game } & League of Legends & 47 & 9.6 \\
\hline & Fortnite & 23 & 4.7 \\
\hline & World of Warcraft & 23 & 4.7 \\
\hline & The Witcher & 19 & 3.9 \\
\hline & Call of Duty & 16 & 3.3 \\
\hline & Counter Strike & 16 & 3.3 \\
\hline & GTA & 16 & 2.4 \\
\hline & Final Fantasy & 12 & 2.4 \\
\hline & Overwatch & 12 & 2.4 \\
\hline & FIFA & 10 & 2.0 \\
\hline & Other & 296 & 61.3 \\
\hline Total & & 490 & 100.0 \\
\hline
\end{tabular}

When the gamer type of the participants in the study were examined, they defined themselves respectively as core gamer (43.5\%), casual gamer $(33.3 \%)$, hardcore gamer $(18.0 \%)$ and newbie $(5.3 \%)$. It is also seen that the most favorite game category was action games $(20.4 \%)$. When the favorite games of the participants were examined, the names of the top 10 favorite games were given because the favorite games of $61.3 \%$ of the participants were different from each other. As seen in the Table 6 , the most favorite game was "League of Legends" with a rate of $9.6 \%$.

Table 8. Purchase Behavior of Game Players

\begin{tabular}{|c|c|c|c|}
\hline Purchase Behavior & & Frequency & $\%$ \\
\hline \multirow[t]{3}{*}{ Purchasing costs of items per a month } & Less than $\% 1$ of my income & 219 & 44.7 \\
\hline & Over $\% 1$ of my income & 157 & 32.0 \\
\hline & None & 114 & 23.3 \\
\hline \multirow[t]{3}{*}{ Purchase items } & Currencies & 110 & 17.4 \\
\hline & Level-up items & 80 & 12.6 \\
\hline & Weaponry & 112 & 17.7 \\
\hline
\end{tabular}




\begin{tabular}{llll} 
& Decorative accessories & 182 & 28.8 \\
& Communication tool & 52 & 8.2 \\
Update PC, console or tablet & Other & 97 & 15.3 \\
& Yes & 348 & 71.0 \\
\hline Total & No & 142 & 29.0 \\
\hline
\end{tabular}

As seen in Table 8, 44.7\% of the participants stated that they allocate less than $1 \%$ of their income for purchasing costs of items per a month. The most purchased items were decorative accessories $(28.8 \%)$, weaponry $(17.7 \%)$ and currencies $(17.4 \%)$, respectively. Again majority of game players indicated that they update their PC, console or tablet (e.g buy a new one) to be able to play new games or the latest version of a game.

Table 9. Total Number and Percentage of Update (PC, console or tablet) In Each Income Group

\begin{tabular}{|c|c|c|c|c|c|c|c|}
\hline & & \multicolumn{4}{|c|}{ Update } & & \\
\hline & & \multicolumn{2}{|c|}{ Yes } & \multicolumn{2}{|c|}{ No } & \multicolumn{2}{|c|}{ Total } \\
\hline & & $\mathrm{n}$ & $\%$ & $\mathrm{n}$ & $\%$ & $\mathrm{~N}$ & $\%$ \\
\hline \multirow[t]{6}{*}{ Income } & Less than min wage & 29 & 52.7 & 26 & 47.3 & 5 & 00.0 \\
\hline & Min wage & 76 & 68.5 & 35 & 31.5 & 111 & 00.0 \\
\hline & Between 2 and 5 times of min wage & 109 & 74.7 & 37 & 25.3 & 146 & 00.0 \\
\hline & Between 6 and 10 times of min wage & 23 & 76.7 & 7 & 23.3 & 30 & 00.0 \\
\hline & Over 10 times of min wage & 17 & 85.0 & 3 & 15.0 & 20 & 00.0 \\
\hline & No monthly income & 94 & 73.4 & 34 & 26.6 & 28 & 00.0 \\
\hline Total & & 348 & 71.0 & 142 & 29.0 & 90 & 00.0 \\
\hline
\end{tabular}

Cross tabulation results of update (PC, console or tablet) versus income groups are represented in Table 9 and it was explored that most of the players with no monthly income update (73.4\%) their game platform (e.g. buy a new one), to access a new game or a new version of the current game.

In order to answer RQ3, the characteristics of game players in terms of different gender, age groups and education levels, crosstab results were examined through bar charts. With this purpose, average time spent playing game per day by gender, age groups and education level were represented via bar charts. Also purchase items, game experience, game platform, gamer type and favorite game categories by gender and age variable are represented in bar charts.

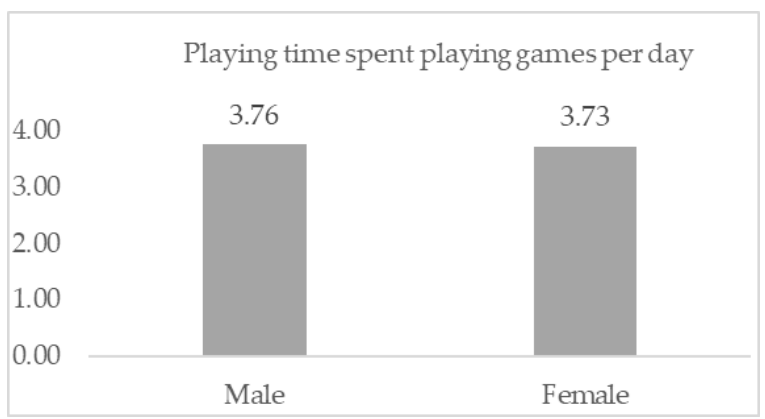

Figure 1. Average Time Spent Playing Games per Day by Gender
In Figure 1, the distribution of the average time spent playing games per day by gender is given. It is seen that men spend an average of 3.76 hours a day and women spend 3.73 hours a day for playing game. There is nearly no difference in playing time for gender.

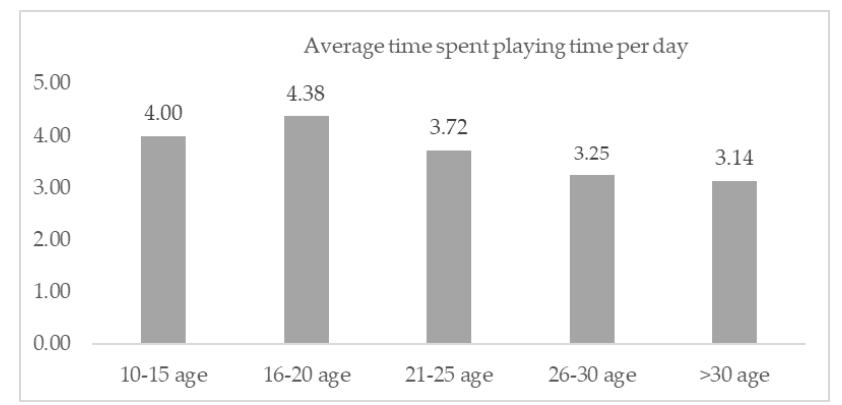

Figure 2. Average Time Spent Playing Games per Day by Age

$$
\text { Group }
$$

In Figure 2, it is seen that the group with the highest average playing time per day (4.38 hours) is the age group of 16-20. Players aged 30 and over were determined as the group that spend the least amount of time ( 3.14 hours per day on average) for playing game. 


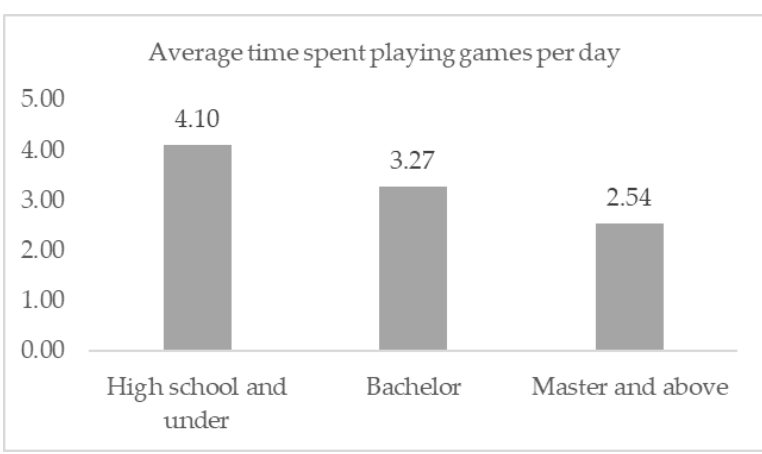

Figure 3. Average Time Spent Playing Games per Day by Education

The distribution of education level and average time spent playing game per day is given in Figure 3. The group with the highest average playing time ( 4.10 hours per day) is at the high school and under education level.

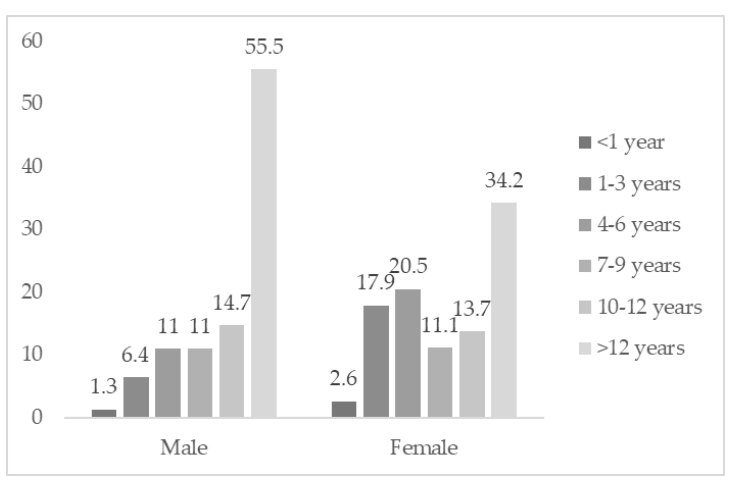

Figure 4. Game Experience by Gender

Figure 4 shows the game experience of players by gender. More than half $(55.5 \%)$ of the male game players have more than 12 years of experience. While $34.2 \%$ of the female game players stated that they have played games for more than 12 years and $20.5 \%$ have $4-6$ years of gaming experience.

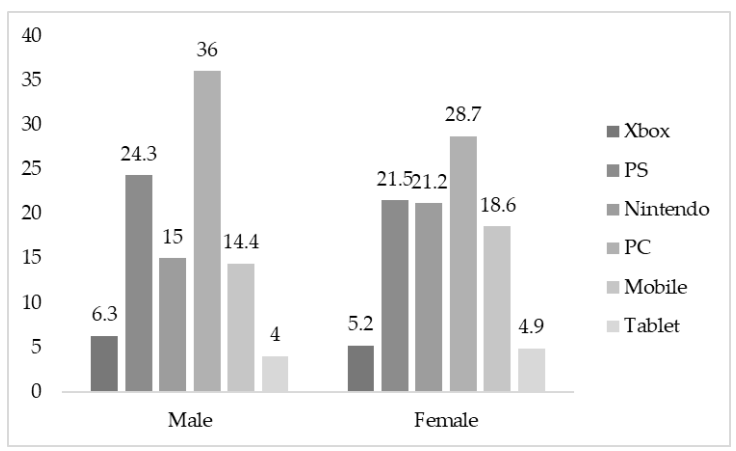

Figure 5. Game Platform by Gender

Figure 5 shows the distribution of game platforms by gender and it is determined that $\mathrm{PC}$ is the most preferred game platform for both women (28.7\%) and men (36\%). The PlayStation console is also the second most preferred game platform for both women $(21.5 \%)$ and men $(24.5 \%)$.

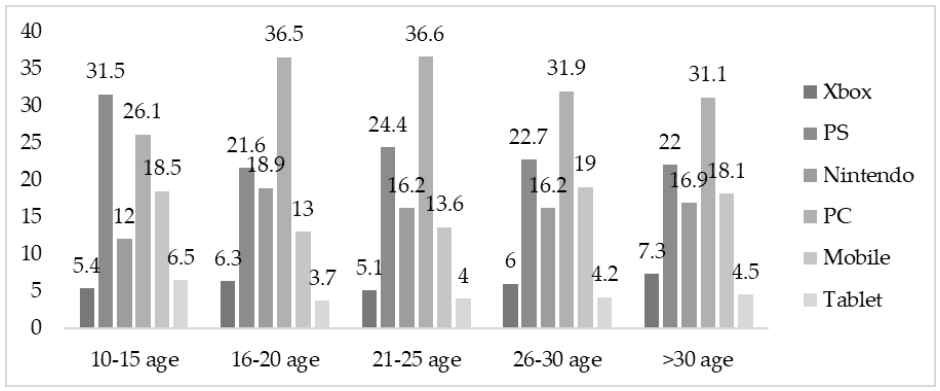

Figure 6. Game Platform by Age Group

When the figure 6 that gives the distribution of game platforms according to age groups is examined, it is seen that PC is the most used platform in all age groups except the 10-15 age group. Players between the ages of 10-15 mostly prefer Playstation $(31.5 \%)$ as a game platform.

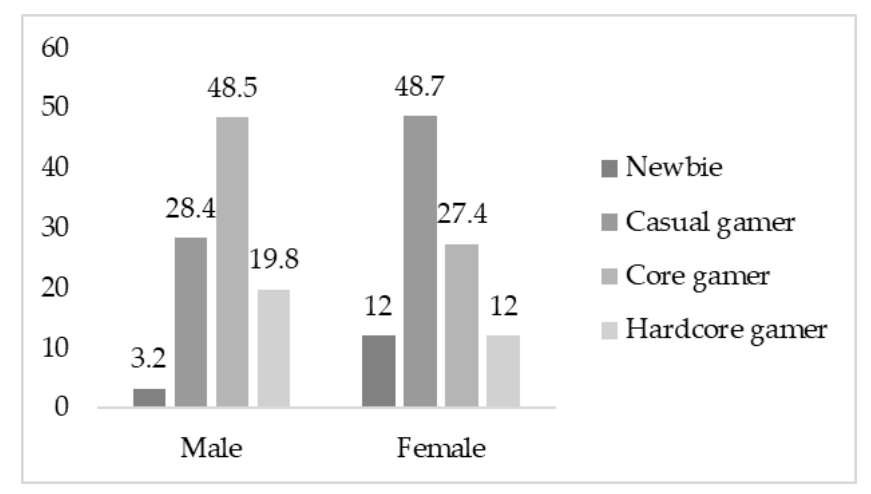

Figure 7. Gamer Type by Gender

Gamer types according to gender are given in Figure 7. While most of the men define themselves as core gamers (48.5\%), women define themselves as casual gamers $(48.7 \%)$. The rate of those who define themselves as newbie among men is quite low compared to women.

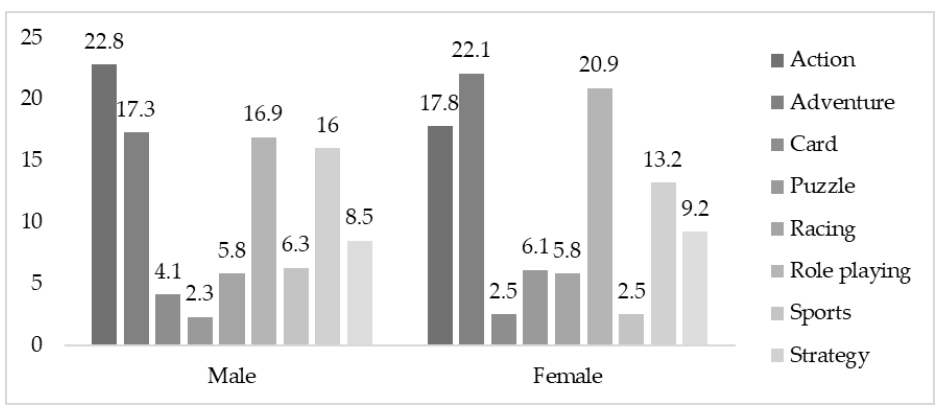

Figure 8. Favorite Game Category by Gender

Figure 8 gives the distribution of favorite game categories by gender. While men mostly prefer to play action $(22.8 \%)$ games, women mostly play adventure (22.1\%) games. The least preferred 
type of game for men is puzzle $(2.3 \%)$. The least preferred game category by women is card $(2.5 \%)$ and sports $(2.5 \%)$.

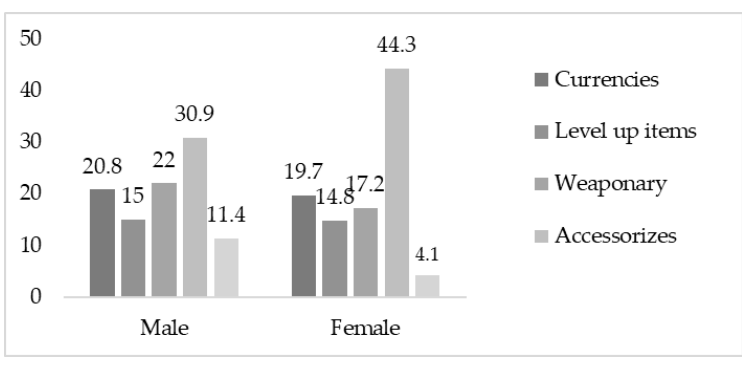

Figure 9. Purchase Items by Gender
When the distribution of purchased items according to gender is analyzed in Figure 8, it is seen that both female (44.3\%) and male $(30.9 \%)$ players buy mostly accessories. Women prefer to buy currencies $(19.7 \%)$ secondly, while men buy weaponry (22\%).

In the last stage of the study, t-test and ANOVA were performed to test the research hypotheses. It was examined if average time spent playing games per day differs significantly in terms of demographic variables such as gender, age, education level and occupation status of game players. According to t-test results, there was no significant difference between average time spent playing games per day and gender $(\mathrm{t}=.146, \mathrm{p}=.884)$, so Hypothesis 1 was not supported.

Table 10. ANOVA Results of Average Time Spent Playing Games by Age, Education and Occupation

\begin{tabular}{|c|c|c|c|c|c|c|c|}
\hline & $\begin{array}{l}\text { Average time spent playing } \\
\text { games (hour/day) }\end{array}$ & $\mathrm{n}$ & Means & $\mathrm{SD}$ & $\mathrm{F}$ & $\mathrm{p}$ & Tamhane \\
\hline \multirow[t]{5}{*}{ Age } & $10-15(1)$ & 43 & 4.00 & 2.34 & 4.33 & $0.002 * *$ & $(2-4)^{*}$ \\
\hline & $16-20(2)$ & 126 & 4.38 & 2.54 & & & $(2-5)^{*}$ \\
\hline & $21-25(3)$ & 166 & 3.73 & 2.50 & & & \\
\hline & $26-30(4)$ & 81 & 3.26 & 2.16 & & & \\
\hline & $>30 \quad(5)$ & 74 & 3.15 & 2.17 & & & \\
\hline \multirow[t]{3}{*}{ Education } & High school and under (1) & 328 & 4.10 & 2.37 & 12.11 & $0.000 * *$ & $(1-2)^{*}$ \\
\hline & Bachelor (2) & 114 & 3.27 & 2.53 & & & $(1-3)^{*}$ \\
\hline & Master and above (3) & 48 & 2.54 & 1.94 & & & \\
\hline \multirow[t]{4}{*}{ Occupation } & Student (1) & 209 & 4.00 & 2.55 & 6.75 & $0.000 * *$ & $(1-2)^{*}$ \\
\hline & Office worker (2) & 115 & 2.90 & 1.84 & & & \\
\hline & Self-employed (3) & 35 & 3.74 & 2.66 & & & \\
\hline & Other (4) & 131 & 4.12 & 2.45 & & & \\
\hline
\end{tabular}

There was a significant difference for the amount of time spent playing games per day in terms of different groups of ages ( $\mathrm{F}=4.33, \mathrm{p}=0.002)$, therefore Hypothesis 2 was supported. Tamhane's multiple comparison tests were performed to identify which particular differences between pairs of means were significant. As a result of the post-hoc test, it was seen that game players aged 16-20 spend more time on playing game than 26-30 age and over 30 age group. In other words, as the age increases, the time allocated to playing games decreases. Statistically significant differences were found in average game play time between different education level of game players $(\mathrm{F}=12.11$, $\mathrm{p}=0.000$ ), so Hypothesis 3 was supported. Game players with high school under education level spend more time in playing game than the players with bachelor and master and above education level. There was also a significant difference for the amount of time spent playing games according to education levels $(\mathrm{F}=6.75, \mathrm{p}=0.000)$, so Hypothesis 4 was supported. Students spend more time on playing game than office workers.

Table 11. ANOVA Results Average Time Spent Playing Games by Gamer Player Type and Game Experience

\begin{tabular}{|c|c|c|c|c|c|c|c|}
\hline & $\begin{array}{c}\begin{array}{c}\text { Average time spent playing } \\
\text { games (hour/day) }\end{array} \\
\end{array}$ & $\mathbf{n}$ & Means & SD & $\mathbf{F}$ & p & Tamhane \\
\hline \multirow[t]{4}{*}{ Gamer Type } & Newbie (1) & 26 & 3.19 & 3.17 & \multirow[t]{4}{*}{39.57} & \multirow[t]{4}{*}{$0.000^{* * *}$} & $(1-4)^{*}$ \\
\hline & Casual gamer (2) & 163 & 2.63 & 1.60 & & & $(2-4)^{*}$ \\
\hline & Core gamer (3) & 213 & 3.87 & 2.04 & & & $(3-4)^{*}$ \\
\hline & Hardcore gamer (4) & 88 & 5.74 & 2.96 & & & \\
\hline \multirow[t]{2}{*}{ Game Experience (Year) } & $<1(1)$ & 8 & 2.63 & 2.26 & \multirow[t]{2}{*}{3.16} & \multirow[t]{2}{*}{$0.008 * *$} & $(2-4)^{*}$ \\
\hline & $1-3(2)$ & 45 & 2.64 & 1.47 & & & $(2-5)^{*}$ \\
\hline
\end{tabular}




\begin{tabular}{lllll}
\hline $4-6(3)$ & 65 & 4.23 & 2.82 & $(2-6)^{*}$ \\
$7-9(4)$ & 54 & 3.61 & 2.30 \\
$10-12(5)$ & 71 & 4.11 & 2.63 \\
& $>12(6)$ & 247 & 3.80 & 2.40 \\
\hline
\end{tabular}

* The mean difference is significant at 0.05 level.

** Statistically significant at the 0.05 level.

According to the results of the Anova test, it was determined that average time spent playing games differs related to the players' gamer type ( $\mathrm{F}=39.57, \mathrm{p}=0.000$ ), so Hypothesis 5 was supported. Looking at the results of the post-hoc analysis, it was seen that hardcore players spend more time on playing games than all other types of players. There was also a significant difference for playing time per day in terms of game experience $(\mathrm{F}=3.16$, $\mathrm{p}=0.008$ ), so Hypothesis 6 was supported. Game players who have 1-3-year experience spend less time on playing game than the players who have 4-6 year, 7-9 year and above 12 years' experience. It was seen that as the experience increases, the time allocated to playing games also increases.

\section{Conclusions, Discussion and Suggestions}

This research is one of the rare academic studies conducted to reveal the detailed profile of game users and their buying habits. While most of the studies have a certain limitation such as online games, mobile games, video games etc., the most obvious difference of this research from the others is that it deals with the game users from a broader perspective. In addition, the study is a first in terms of being conducted at the Gamescom fair which is the world's largest trade fair for video games. When the literature is examined, a face to face study with game players in a game fair hasn't been found. It is very important for marketers, game developers and the industry to recognize potential and existing game users in the developing and growing game world. As a result of the literature review, the main lines of the study were determined based on the missing details. For example, unlike many previous studies, this study was conducted for game players who play both online and offline games without specifying a specific game. Another missing found in the literature was the playing place preferences such as home, cafe and workplace and it was seen that any information wasn't given in previous studies on this subject. It has been determined that game platforms (e.g PC, Xbox, PlayStation) are also not examined in detail. For the reasons explained above, this paper aims to determine the demographics and characteristics of game players, and to specify whether or not there is a relationship between different characteristics of game players and time spent on game playing.

According to the results regarding the demographics of the game players, it has been determined that the gamers are primarily women. The gender difference in gaming has been studied by many researchers. There's a long-held stereotype that game users are mostly men and spend more time on playing games. However, there has been a significant increase in the number of female gamers recently and the perception that games are mostly an activity for men has started to change. In this study it was seen that participants are mostly female gamers. In addition to this, independent t-tests revealed no gender differences in terms of time spent on game playing. This result supports the recent studies that the stereotype of the gamer as a male no longer exists and also shows that there will be a significant change in the marketing literature. Generation $\mathrm{Z}$ has started to exist not only in the game market but also in all markets. Thus it is necessary to update studies on common gender-based purchasing habits. When we look at the age distribution of gamers, the excess of young adults draw attention. In contrast to stereotype, most of the players were not adolescents. Majority of gamers have a low education qualification and many of them continue their education.

According to the results regarding the characteristics of the game players, it was determined that the participants had a game experience of more than 12 years. The number of players with less than 1 year of experience was quite low and these were mostly newbies and casual players. Participants play games for an average of 3.76 hours a day and an average of 5.16 days per week. The fact that $40.6 \%$ of the participants play games every day is a significant result about game addiction and should be studied in future studies related to the game. Examining game addiction in future studies on the game will be significant for the literature. As mentioned above there was no gender differences in terms of time spent on game playing, both male and female spend nearly same time on playing. Players aged between 16-20 years spend much time on playing game. Significant difference was found between playing time and age, and in accordance with the stereotype younger players play more than older players. This result supports previous studies. For example, Griffiths et al. (2003), stated that individuals under the age of 30 play more games. Herodotou \& Kambouri (2015), also stated that there is an inverse proportion between age and the duration of playing games. According to Herodotou \& Kambouri (2015), the duration of playing games decreases as age increases. On the other hand, there are also studies with different results in the literature. For example, Williams et al. (2008) found that the time to play games 
is directly proportional to age, and they found that the time to play games increases with age. According to the authors, today's adults play more than previous generations.

It was also found that high school and under students spend more time on playing games than those of other education levels. There was a significant difference between the occupational groups in terms of average time spent on playing gam and it was determined that the students play longer than the office workers. It can be said that the reason for all these consequences is that young people have more free time and less responsibility than adults. Experience also makes a difference in terms of time spent on game playing. As experience increases, the time allocated to playing games increases.

Participants mostly prefer to play games at home and on their personal computers (PCs). PC and consoles in total (Xbox/PS/Nintendo) were found to be the dominant gaming platforms. According to a study conducted in 2019, PC is the most important gaming platform for developers (Statista, 2020d). However, this is not the case for mobile and tablet. Despite the rapid increase in mobile games in recent years, these are among the least preferred gaming platforms. When the game platform preference was evaluated in terms of gender, men mostly prefer $\mathrm{PC}$ and PlayStation as a gaming platform. While women prefer to play on PC and PlayStation the most, Nintendo was added to this. Women also play mobile games more than men. PC was the most preferred game platform in all age groups except the 10-15 age group. The majority of the 10-15 age group were playing on PlayStation. It was revealed that the participants preferred to play online games. Because the gaming industry is one of the sectors most affected by the digital age and the average age of the participants is low in this research, it is an expected result that online games will be preferred more.

Considering the types of players, it was seen that there was more core and casual gamers among the participants. Newbies who have just started the game and have lower game experience are the least in number. Gamer type make difference in terms of time spent on game playing. Hardcore gamers play longer than all gamer types. Almost half of the male participants were core gamers, while female participants are casual gamers. The number of newbies in women was higher than in men. Newbie gamers are game players who do not have much information about the game, who are inexperienced and usually play games to relieve their boredom (Rogers, 2012). However, the participation of female newbie game players to the world's most known game fair such as Gamescom contradicts this definition. This result shows that the definition of game player types needs to renew according to the new generation of game players.
Action, adventure, role playing and strategy were the most preferred game categories. While men mostly play action games, women play adventure games. The least played game type for men was puzzle, while for women it was determined as card and sports. According to Bonanno and Kommers (2005), a large number of women prefer puzzle, adventure, fighting, and management games. Males prefer first-person shooters, roleplaying games, sports, and strategy games, according to the study. In a study by Romrell (2014) that looked at game type preferences by gender, it was discovered that men prefer games with a lot of action and competitiveness, while women prefer logic, puzzle, or skill training games. In this study, unlike the others mentioned above, it was observed that most preferred top three game types (action, adventure, role playing) were the same for both male and female players. Players were finally asked about their favorite games, and League of Legends, Fortnite, and World of Warcraft were identified as their favorite games.

The majority of players spend less than $1 \%$ of their monthly income on purchasing items, and mostly buy decorative accessories, weaponry and currencies. Men spend more money on items than women. However, both women and men mostly prefer to buy accessories. Majority of game players update their PC, console or tablet (e.g buy a new one) to be able to play new games or the latest version of a game. As an unexpected result, a large proportion of those with no monthly income stated that they update their game platform (eg buy a new one) when necessary (to access a new game or to access a new version of an existing game). Almost all of this group consists of game players who were students and between the ages of 10-20. This situation shows that even if game players do not have income, they continue their game play habits.

As a conclusion, this study is important to put forward who are these potential consumers in terms of demographic variables such as age, gender, education, occupation and income. Besides knowing who these people are, it is essential to know their gaming habits such as game experience, game frequency, game category presences, favorite games, purchase behaviors etc. It is also very important for the developing game industry and the game market to answer questions such as who plays how much, which age group prefers which game types, who buys what etc. Most of the results suggest that common game player stereotypes no longer exist. The demographic and characteristic findings have implications for future research on game players.

This study is limited to the game players participating in the Gamescom fair in Cologne, Germany. In subsequent studies, a similar study could be conducted on game players living in Turkey. Different variables and questions can be added to the 
study or different research methods can be used to determine the player profile, gaming and buying habits.

\section{References}

1. Ankara Development Agency (2015). Dijital oyun sektörü raporu, Ankara.

2. Bartle, R. (1996). Clubs, hearts, Clubs, diamonds, spades: Players who suit MUDs, The Journal of Virtual Environments, 1(1), 1-19.

3. Bonanno, P., \& Kommers, P. A. (2005). Gender differences and styles in the use of digital games, Educational Psychology, 25(1), 13-41. https://doi.org/10.1080/0144341042000294877

4. Cole, H., \& Griffiths, M. D. (2007). Social interactions in massively multiplayer online roleplaying gamers, Cyber Psychology \& Behavior, 10(4),

575-583.

https://doi.org/10.1089/cpb.2007.9988

5. Deloitte (2019). Hayatımızın merkezindeki mobil teknolojiler, Deloitte Global Mobil Kullanıcı Anketi 2019: Türkiye Yönetici Özeti. Available at: https://www2.deloitte.com/tr/tr/pages/technologymedia-and-telecommunications/articles/TR-GMCS2019.html (Accessed: 13.02.2021).

6. Electronic Arts (2019). About Gamescom 2019. Available at: https://www.ea.com/gamescom-2019 (Accessed: 14.10.2020).

7. Etikan, I., Musa, S. A., \& Alkassim, R. S. (2016). Comparison of convenience sampling and purposive sampling, American Journal of Theoretical and Applied Statistics, 5(1), 1-4. https://doi.org/10.11648/j.ajtas.20160501.11

8. Griffiths, M. D., Davies, M. N. O., \& Chappell, D. (2003). Breaking the stereotype: The case of online gaming, Cyber Psychology \& Behavior, 6(1), 81-91. https://doi.org/10.1089/109493103321167992

9. Griffiths, M. D., Davies, M. N. O., \& Chappell, D. (2004a). Demographic factors and playing variables in online computer gaming, Cyber Psychology \& Behavior, 7(4), 479-487. https://doi.org/10.1089/cpb.2004.7.479

10. Griffiths, M. D., Davies, M. N. O., \& Chappell, D. (2004b). Online computer gaming: A comparison of adolescent and adult gamers, Journal of Adolescence, 27 , 87-96. https://doi.org/10.1016/j.adolescence.2003.10.007

11. Güvenli Web (2017). Dijital oyunlar raporu, Available at: https://www.guvenliweb.org.tr/dosya/82MsL.pdf (Accessed: 12.01.2021).
12. Hainey, T., Connolly, T., Stansfield, M., \& Boyle, E. (2011). The differences in motivations of online game players and offline game players: A combined analysis of three studies at higher education level, Computers and Education, 57(1), 2197-2211. https://doi.org/10.1016/j.compedu.2011.06.001

13. Herodotou, C., Kambouri, M., \& Winters, N. (2015). What characteristics of the gamers' profile should be taken into account in player centered game design? in Workshop Proceedings of the 11th International Conference on Intelligent Environments, 2015, 289297. https://doi.org/10.3233/978-1-61499-530-2-289

14. Hsiao, K. L., \& Chen, C. C. (2016). What drives inapp purchase intention for mobile games? An examination of perceived values and loyalty, Electronic Commerce Research and Applications, 16, 18-29. https://doi.org/10.1016/j.elerap.2016.01.001

15. Karahisar, T. (2013). Türkiye'de dijital oyun sektörünün durumu, in 1. International Art Symposium Proceedings Book, 21-23 November 2013, 107-113.

16. Lee, H. M., Zhang, P., \& Mehta, M. R. (2020). Effect of competitors' ewom in the mobile game market, Journal of Computer Information Systems.

17. Lin, H. H., \& Wang, Y. H., (2006). An examination of the determinants of customer loyalty in mobile commerce contexts. Information \& Management, 43 (3), $271-282$. https://doi.org/10.1016/j.im.2005.08.001

18. Lipinski, A. V. J. Weber, H., Kölle, R., \& Mandl, T. (2017). Gamification elements and their perception by different gamer types - A case study for a project management software, in Proceedings of the 15th International Symposium of Information Science (ISI 2017), 131-144.

19. PC Games Insider (2019). 373,000 people attended Gamescom 2019, Available at: https://www.pcgamesinsider.biz/news/69579/373000 -people-attended-gamescom-2019

20. Pew Research Center (2018). Early benchmarks show 'post-millennials' on track to be most diverse, besteducated generation yet. Available at: https://www.pewresearch.org/socialtrends/2018/11/15/early-benchmarks-show-postmillennials-on-track-to-be-most-diverse-besteducated-generation-yet/psdt-11-1518 postmillennials-00-00/ (Accessed: 13.02.2021).

21. Poels, Y., Annema, J. H., Verstraete, M., Zaman, B., \& Grooff, D. D. (2012). Are you a gamer? A qualitative study on the parameters for categorizing 
casual and hardcore gamers. Iadis International Journal on www/internet, 10 (1), 1-16.

22. Rafdinal, W., \& Qisthi, A. (2020). In-game factors and technology acceptance factors in increasing intention to play online game, in Proceedings of Tourism Development Centre International Conference, Tourism Development Centre International Conference (TDCIC) October 2019, 281-296.

23. Rogers, A. (2012). Launching and marketing a mobile game: Strategy and consumer perceptions. (Unpublished thesis), Helsinki Metropolia University: Finland.

24. Romrell, D. (2014). Gender and gaming: A literature review, in annual meeting of the AECT International Convention, Hyatt Regency Orange County, Anaheim, CA, 22 November 2014, 170-182.

25. San-Martin, S., Jimenez, N., Camarero, C., \& SanJosé, R. (2020). The path between personality, selfefficacy, and shopping regarding games apps, Journal of Theoretical and Applied Electronic Commerce Research, $15(2)$, $59-75$. https://doi.org/10.4067/s0718-1876202000020010

26. Scharkow, M., Festl, R., Vogelgesang, J., \& Quandt, T. (2015). Beyond the "core-gamer": Genre preferences and Gratifications in Computer Games. Computers in Human Behavior, 44, 293-298. https://doi.org/10.1016/j.chb.2014.11.020

27. Schuurman, D., De Moor, K., De Marez, L., \& Van Looy, J. (2008). Fanboys, competers, escapists and time-killers: A typology based on gamers' motivations for playing video games, in Proceedings of The 3rd International Conference on Digital Interactive Media in Entertainment and Arts. Athens, Greece: ACM, 46-50.

28. Statista (2020a). Mobile games revenue worldwide from 2019 to 2023. Available at: https://www.statista.com/statistics/536433/mobilegames-revenue-worldwide/ (Accessed: 14.10.2020).

29. Statista (2020b). Video game console sales worldwide for products total lifespan as of September 2020. Available at:

https://www.statista.com/statistics/268966/totalnumber-of-game-consoles-sold-worldwide-byconsole-type/ (Accessed: 13.01.2021).

30. Statista (2020c). Mobile gaming- statistics \& facts. Available at: https://www.statista.com/topics/1906/mobilegaming/\#dossierSummary chapter1 (Accessed: 14.10.2020).
31. Statista (2020d). The most important gaming platforms in 2019. Available at: https://www.statista.com/chart/4527/game-

developers-platform-preferences/ (Accessed: 15.02.2021).

32. Terlutter, R., \& Capella, M. L. (2013). The gamification of advertising: Analysis and research directions of in-game advertising, advergames, and advertising in social network games, Journal of Advertising, $\quad 42(2-3), \quad 95-112$. https://doi.org/10.1080/00913367.2013.774610

33. Venkatesh, V., Thong, J., \& Xu, X. (2012). Consumer acceptance and use of information technology: Extending the unified theory of acceptance and use of technology. MIS Quarterly, 36(1), 157-178. https://doi.org/10.2307/41410412

34. VGChartz (2020). Platform totals. Available at: https://www.vgchartz.com/analysis/platform_totals/ (Accessed: 13.01.2021).

35. Williams, D., Yee, N., \& Caplan, S. E. (2008). Who plays, how much, and why? Debunking the stereotypical gamer profile, Journal of ComputerMediated Communication, 13, 993-1018. https://doi.org/10.1111/j.1083-6101.2008.00428.x

36. Yalçın Irmak, A., \& Erdoğan, S. (2016). Ergen ve genç erişkinlerde dijital oyun bağımlılığı: Güncel bir bakış, Türk Psikiyatri Dergisi, 27(2), 128-37. https://doi.org/10.5080/u13407 